\title{
Analysis of Economic Effect and Mechanism of Basic Medical Insurance for Urban Employees in China
}

\author{
Yi Li $\mathbb{D}^{1}{ }^{1}$ Xia Zhang $\mathbb{D},{ }^{2,3}$ and Xia Yang ${ }^{4,5}$ \\ ${ }^{1}$ School of Finance, Hubei University of Economics, Wuhan, Hubei 430205, China \\ ${ }^{2}$ School of Finance, Zhongnan University of Economics and Law, Wuhan, Hubei 430073, China \\ ${ }^{3}$ Financial Development and Financial Security Research Center, Hubei University of Economics, Wuhan, Hubei 430205, China \\ ${ }^{4}$ Economics and Management School, Wuhan University, Wuhan, Hubei 430072, China \\ ${ }^{5}$ Research Center for Risk, Wuhan University, Wuhan, Hubei 430072, China \\ Correspondence should be addressed to Xia Zhang; zxia_87@163.com
}

Received 31 May 2021; Revised 25 July 2021; Accepted 17 August 2021; Published 2 September 2021

Academic Editor: Wei Zhang

Copyright (c) $2021 \mathrm{Yi} \mathrm{Li} \mathrm{et} \mathrm{al.} \mathrm{This} \mathrm{is} \mathrm{an} \mathrm{open} \mathrm{access} \mathrm{article} \mathrm{distributed} \mathrm{under} \mathrm{the} \mathrm{Creative} \mathrm{Commons} \mathrm{Attribution} \mathrm{License,} \mathrm{which}$ permits unrestricted use, distribution, and reproduction in any medium, provided the original work is properly cited.

\begin{abstract}
The purpose of social basic medical insurance is to solve the problem that "medical treatment is difficult and expensive." With the implementation of new technologies and new diagnosis and treatment methods, the price of medicine has risen sharply. Under this background, can basic medical insurance still relieve the economic pressure of patients? Based on the tracking data of China Health and Nutrition Survey (CHNS) from 2006 to 2015, by constructing Heckman sample selection model, the paper finds that the basic medical insurance for urban employees (UEBMI) leads to an increase in medical expenses, among which only $0.61 \%$ can be attributed to the release of normal medical demand and $114.47 \%$ can be attributed to moral hazard; for flexible employees, $249.52 \%$ increase can be attributed to adverse selection. Based on this, the paper puts forward two suggestions: first, promoting Hierarchical Treatment Model to control the growth of medical expenses and second, guiding flexible employees to participate in the UEBMI.
\end{abstract}

\section{Introduction}

Medical insurance is a risk sharing mechanism between healthy people and unhealthy people or between health and sickness. Its direct function is to ensure people's financial accessibility of medical services when they are sick [1]. China's multilevel medical security system includes social basic medical insurance, supplementary medical insurance, commercial medical insurance, and medical assistance. Among them, the universal coverage of social basic medical insurance is the main health policy promoted in China's medical reform, and it is also a policy that attracts worldwide attention. However, this policy costs so much, and whether such heavy expenditure has played its due role has drawn scholars' debate over years.

Studies by scholars [2-6] have all confirmed that compared with patients who bear medical expenses alone, patients with medical insurance face a lower medical price, and this distorted medical service prices may lead to an increase in utilization of medical services and medical expenses. Common problems in medical market, such as adverse selection mentioned in [7-12] and moral hazard mentioned in [13-16], will also lead to the waste of medical resources, resulting in significantly higher growth rate of medical expenses per capita than income growth. Although there are many research results on this topic, the existing studies still have some limitations: First, they pay more attention to the "burden reduction" effect of medical insurance on vulnerable groups such as the elderly and children and analyze the impact of the new rural cooperative medical insurance on the patients' economic burden, while paying insufficient attention to the employees with only basic medical insurance. Second, there has been no consensus of views when separating adverse selection effect from moral hazard effect. Although many scholars agree that moral hazard and adverse selection, which are prevalent in 
the medical insurance market, will lead to a substantial increase in medical expenses, the decomposition of their effects is still a "roadblock" in empirical research. At present, scholars mainly use three methods to separate these two effects: (1) distinguishing them through natural experiments or random experiments, but natural experiments are rare and random experiments are costly; (2) according to the time sequence of occurrence, using dynamic data to separate moral hazard from adverse selection; (3) using the characteristics of specific insurance markets and types. Scholars have different views on which method is more reasonable. In this paper, we study the economic effects of UEBMI, while the economic effects are affected by adverse selection and moral hazard. Adverse selection has nothing to do with income in UEBMI; it can occur in both high-income and low-income groups. However, people with fixed jobs are forced to participate in insurance based on enterprises, and there will be no adverse selection, while flexible employees without fixed jobs can freely choose whether to participate in the insurance, and adverse selection may occur; that is, whether adverse selection occurs depends on occupation. However, the occurrence of moral hazard is related to the income. When the income is low, the high medical expenses caused by moral hazard cannot be borne, and there is basically no moral hazard problem; on the other hand, when the income is high, moral hazard will occur in order to get better medical effect and service. Therefore, this paper chooses the third way to separate moral hazard and adverse selection.

This article focuses on the economic effect of medical insurance on employees who only have basic medical insurance. This group of people is also an economically vulnerable group, whose resistance to disease risk is weak. Without health insurance, if they suffer from major diseases, the economic impact on families will be very strong, and it is likely to result in active or passive abandonment of treatment. By purchasing UEBMI, the risk of high medical expenses will be transferred to medical insurance agencies, which will pay part of the medical expenses in case of illness, stimulating medical demand, and increasing medical expenses. However, due to the limited level of financing for UEBMI, the insured population still needs to bear a certain proportion of medical expenses. Therefore, with the increase of the total medical expenses, the self-paid expenses of the insured may also increase. Since the original intention of UEBMI is to solve the problem of "medical treatment is difficult and expensive," how much of a role does UEBMI play when employees suffer from diseases? Eventually does it reduce or increase the medical burden of employees? This requires analyzing the economic effects of UEBMI.

On the other hand, the reasons for medical expenses increasing include moral hazard effect and adverse selection effect, in addition to the decrease in the price actually paid by patients, which stimulates medical demand, that is, the release of normal medical demand. Moral hazard effect is the unreasonable increase of medical expenses caused by information asymmetry, which is manifested as excessive medical treatment, minor illness, collusion between doctors and patients, and prescribing "big prescriptions." Adverse selection effect is that people with poor health are more willing to buy medical insurance, which leads to an increase in the number of illnesses and an unreasonable increase in medical expenses. Considering that when the insureds' income level is low, they do not have enough financial ability to bear the "high" medical expenses, they will not take the initiative to increase medical expenses. Therefore, when seeing a doctor, they will be limited to reasonable treatment, and there is basically no moral hazard. Only when the insureds' income level is high, they have sufficient financial strength to enjoy better services, pursue better treatment, and thus generate moral hazard. At the same time, considering that the basic medical insurance for urban employees needs to take enterprises as the carrier, which is internally mandatory, employees of enterprises cannot freely choose whether to participate in the insurance. At this time, there is no adverse selection. On the other hand, flexible employees without fixed jobs can freely choose whether to participate in the insurance, and this will inevitably lead to the result of "bad money drives out good money" and there will be adverse selection. Therefore, based on the economic effect of UEBMI, this paper analyzes the mechanism of medical cost growth, distinguishes moral hazard effect and adverse selection effect by income heterogeneity analysis and occupation heterogeneity analysis, and provides theoretical foundation for the implementation of the UEBMI policy in the future.

\section{Data, Variables, and Models}

2.1. Data and Variables. The data used in this paper comes from the China Health and Nutrition Survey (CHNS), an international collaborative project between the Population Center at the University of North Carolina and the National Institute for Nutrition and Health (NINH, former National Institute of Nutrition and Food Safety) at the Chinese Center for Disease Control and Prevention (CCDC). CHNS has 10 phases of tracking data. This paper uses 4 phases of tracking data from 2006 to 2015. The latest data was released in 2018, involving about 7,200 families with over 30,000 interviewees in 15 provinces.

When measuring the economic burden of urban workers, this paper chooses "total medical expenses" and "self-paid medical expenses" as the explained variables. The explanatory variables include the processing variables "whether to participate in UEBMI or not" and period variables and their interaction. According to [17], the control variables include the population characteristics, family characteristics, and other health characteristics of the insured. The specific variable settings are shown in Table 1.

In this paper, after eliminating samples with obvious anomalies of key variables and missing variables, merging the subdatabases, and deleting the mismatched samples, 83,837 samples remained. Because the CHNS questionnaire started to include questions related to the UEBMI in 2009, only the three periods of data in 2009, 2011, and 2015 were available in this study. In order to accurately investigate the implementation effect of the UEBMI and compare the effects before and after the purchase of UEBMI, this paper also retains the data of the previous period, that is, the data of 
TABLE 1: Variable description and assignment.

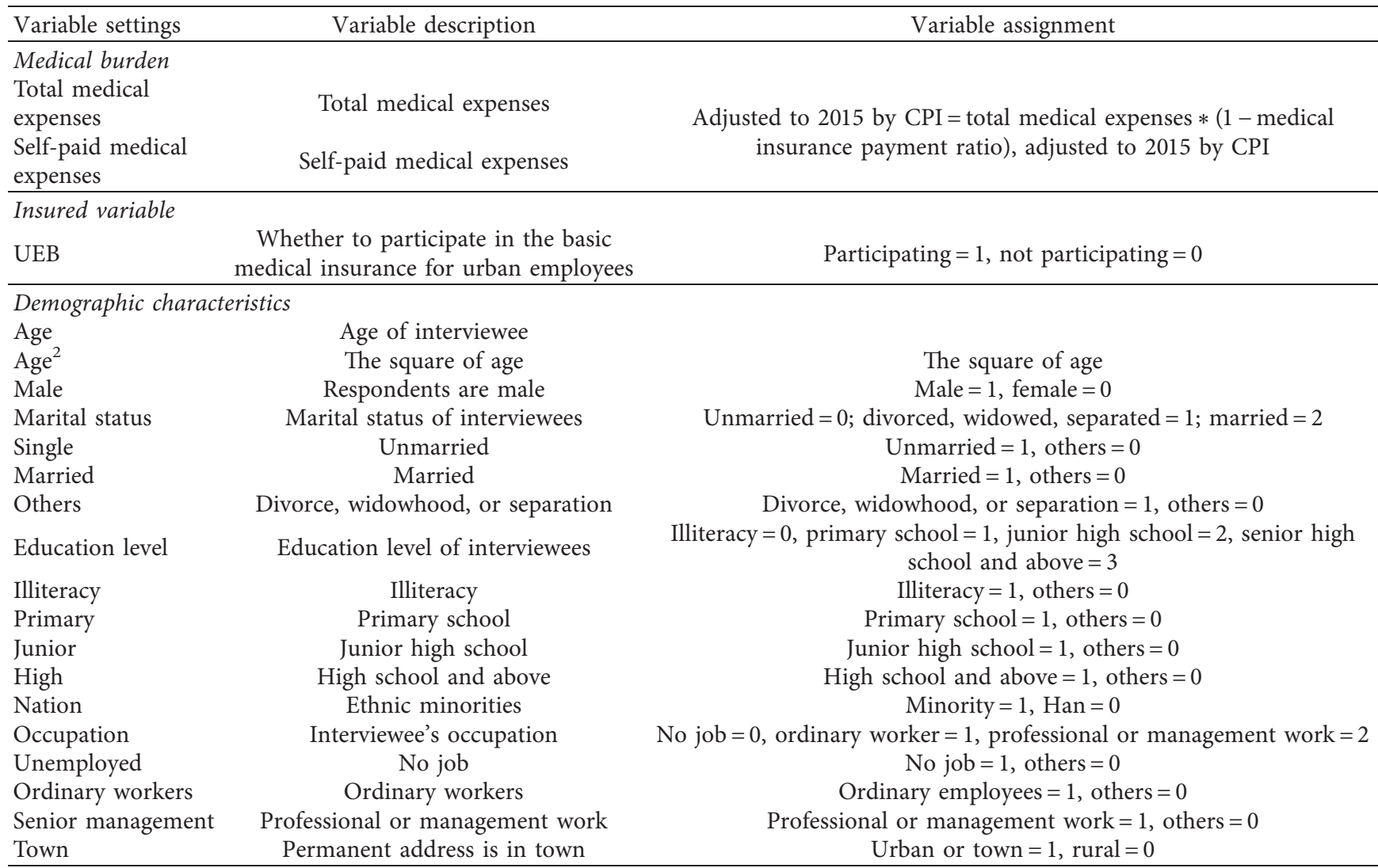

Family characteristics

Family size

Any other relatives

Household income

per capita

Health characteristics

Smoking

Alcohol

Illness or injury

Previous medical history
Number of households

Are there any other relatives?

Household income per capita

$$
\text { Yes }=1, \text { none }=0
$$

Adjusted to 2015 by CPI

Smoking or not
Do you drink alcohol?
Have you been sick or injured in the past
four weeks?
four weeks?

Previous medical history
Smoking and still smoking $=1$, others $=0$ Almost every day or 3-4 times a week $=1$, others $=0$

$$
\text { Yes }=1, \text { no }=0
$$

Have been diagnosed as suffering from or having suffered from one or more of the seven diseases below: hypertension, diabetes, myocardial infarction, stroke or transient ischemia, tumor, fracture, and asthma $=1$, none $=0$
2006, with 40054 remaining samples. In order to analyze the net effect of UEBMI, this paper takes the samples that did not purchase any medical insurance in the previous period and only purchased the UEBMI in the next period as the treatment group, and takes the samples that did not purchase any medical insurance in the two periods as the control group. At this time, there are 1860 samples left, with 930 samples in each period, including 426 samples in the treatment group and 504 samples in the control group. Descriptive statistical results of these samples are shown in Table 2.

The results reported in Table 2 show that before the purchase of UEBMI, the total medical expenses of the treatment group were far less than those of the control group. However, after the purchase of insurance, the medical expenses of the control group decreased slightly, while the medical expenses of the treatment group increased greatly, from 278.8 yuan to 1274 yuan, exceeding the data of the control group. The change direction of self-paid medical expenses is consistent with the total medical expenses except that after purchasing insurance, the self-paid medical expenses of the treatment group are still less than those of the control group. None of the above results are significant. They seem to indicate that insurance has not reduced but increased the insured's economic burden, which means a countereffect and may even cause us to doubt the function of UEBMI. However, due to the differences in risk awareness, health level, and tendency to seek medical treatment between the groups who buy insurance and those who do not, Table 2 does not control other variables, so the results need 
to be further verified. Of course, the possibility that there will be some data exceptions in the table cannot be ruled out, because of the difference in the caliber of the respondents who filled in the survey. This may have happened when they were interviewed; the interviewers filled in the diploma they had not obtained in the first period, and they filled in the diploma they had obtained in the second period. This paper uses the Heckman sample selection model to empirically analyze the economic effect of UEBMI, and thus evaluate the economic effect of medical insurance more objectively.

2.2. Model Constructing. A lot of medical expense values are zero, which might be caused by unnecessary medical treatment, choosing not to seek medical advice because of the medical costs, or the inconvenience of seeking medical advice. In this case, direct estimation will lead to biased results, while Heckman sample selection model can correct the selective bias caused by the phenomenon of sample selfselection; that is, the model can correct the selective bias in estimation caused by the nil expenditure. On the other hand, Heckman sample selection model does not have to determine whether the two processes of "whether medical expenditure occurs" and "if it occurs, how much will pay" are independent of each other. Therefore, this paper constructs Heckman sample selection model to estimate the economic effect of UEBMI. When examining the impact of UEBMI on medical expenditure, considering that the increase of medical expenditure is mostly caused by the progress of medical technology and the rising price of medicine, in order to control the common time trend of the treatment group and the control group, this paper adopts the panel structure of difference in difference (DID) according to [5] and sets the sample selection model as follows:

$$
P\left(I_{i}=1\right)=P\left(\beta_{0}+\beta_{1} \text { treat }_{i}+\beta_{2} \text { time }_{t}+\beta_{3} \text { treat }_{i} \times \text { time }_{t}+\beta_{4} X_{\text {tid }}+\delta_{s}+\varepsilon_{\text {tid }}>0\right) .
$$

Equation (1) is a selection equation, considering the influence of treatment variable, time variable, control variables, and provincial variable on the dependent variable. It uses probit model to calculate the probability of positive medical expenses for the sample $i$. The expenditure equation for the second step is:

$$
\ln \left(\text { pay }_{\text {tid }} \mid I_{i}=1\right)=\beta_{0}^{\prime}+\beta_{1}^{\prime} \text { treat }_{i}+\beta_{2}^{\prime} \text { time }_{t}+\beta_{3}^{\prime} \text { treat }_{i} \times \text { time }_{t}+\beta_{4}^{\prime} X_{\text {tid }}+\rho \sigma_{2} \lambda_{i}+\delta_{s}^{\prime}+\varepsilon_{\text {tid }}^{\prime}
$$

Equation (2) can estimate the effects of various factors on medical expenses. In (1) and (2), pay tid $_{\text {id }}$ is the dependent variable, which can be total medical expenses or self-paid medical expenses for sample $i$ in period $t$. The dummy variable treat ${ }_{i}$ indicates whether UEBMI is purchased for sample $i$. The samples that purchased UEBMI are classified as the treatment group with a value of 1 , and the samples that did not purchase the UEBMI are classified as the control group with a value of 0 . Its coefficient $\beta_{1}^{\prime}$ reflects the difference between the treatment group and the control group in the first phase, that is, the group difference. The dummy

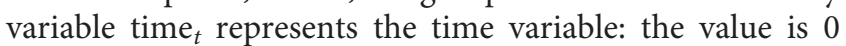
when all samples did not purchase any medical insurance in the first period and 1 when some samples purchased UEBMI in the second period. Its coefficient $\beta_{2}^{\prime}$ reflects the difference in the control group between Phase 1 and Phase 2, that is, the time difference, which includes the increase in the price of medical expenses. treat $\times$ time is the interactive effect of the two variables: its value is 1 only when both variables equal 1 ; otherwise, it is 0 . The difference in difference controls both the group effect and the time effect and can solve the endogeneity problem well. Its coefficient $\beta_{3}^{\prime}$ excludes the effect of rising medical prices and measures the net effect of UEBMI. The calculation principle of DID is shown in Table 3. $X_{\text {tid }}$ are the control variables, including age, gender, nationality, marital status, education level, occupation, permanent address, income, previous medical history, smoking, and drinking. Whether there are any other relatives is also added as the control variable in the selection equation. $\delta_{s}$ is a provincial dummy variable. The sample size is small after processing, and the sample size is insufficient after controlling the municipal variable; thus, only the provincial variable is controlled. $\rho$ is the correlation coefficient of $\varepsilon_{\text {tid }}$ and $\varepsilon_{\text {tid }}^{\prime} . \sigma_{1}$ is the standard deviation of equation (1). $\sigma_{2}$ is the standard deviation of equation (2). $\lambda_{i}$ is the inverse Mills ratio.

\section{Empirical Results and Explanations}

3.1. The Overall Impact of Medical Insurance on Medical Expenses. Table 4 reports the results of the Heckman sample selection model. The results indicate that after purchasing the UEBMI, the probability of positive medical expenses of the insured decreases by $2.09 \%$, and the result is not significant, which means that the UEBMI may slightly reduce the utilization of medical services. The reason may be that the insureds absorb more health knowledge and realize the importance of healthcare due to medical insurance; then, the number of illnesses decreases, which leads to the reduction of medical services utilization. It may also be because the medical expenses rise due to medical insurance. Even if the insured has medical insurance to reimburse part of the medical expenses, the actual amount paid in the end is higher than that before the insurance, which makes the 
TABLE 2: Differences between treatment group and control group.

\begin{tabular}{|c|c|c|c|c|c|c|c|}
\hline \multirow[b]{2}{*}{ Variable } & \multicolumn{4}{|c|}{ Previous period } & \multicolumn{3}{|c|}{ Subsequent period } \\
\hline & $\begin{array}{c}\text { (1) } \\
\text { Full sample }\end{array}$ & $\begin{array}{c}\text { (2) } \\
\text { Treatment group }\end{array}$ & $\begin{array}{c}\text { (3) } \\
\text { Control group }\end{array}$ & $\begin{array}{c}(4) \\
T \text { value }\end{array}$ & $\begin{array}{c}\text { (5) } \\
\text { Treatment group }\end{array}$ & $\begin{array}{l}\text { (6) } \\
\text { Control group }\end{array}$ & $\begin{array}{c}(7) \\
T \text { value }\end{array}$ \\
\hline Total medical expenses & 799.369 & 278.8 & 846.5 & 1.418 & 1274 & 781.2 & -1.131 \\
\hline Self-paid medical expenses & 623.33 & 223.7 & 846.5 & 1.567 & 516.7 & 734.5 & 0.658 \\
\hline Age & 47.749 & 45.88 & 46.67 & 0.775 & 48.84 & 49.47 & 0.618 \\
\hline Male & 0.487 & 0.512 & 0.466 & -1.382 & 0.512 & 0.466 & -1.382 \\
\hline Marital status & 1.688 & 1.688 & 1.671 & -0.387 & 1.742 & 1.661 & $-1.949^{*}$ \\
\hline Unmarried & 0.106 & 0.127 & 0.109 & -0.832 & 0.094 & 0.095 & 0.0700 \\
\hline Married & 0.794 & 0.815 & 0.780 & -1.311 & 0.836 & 0.756 & $-2.998^{* * *}$ \\
\hline Others & 0.100 & 0.059 & 0.111 & $2.834^{* * *}$ & 0.070 & 0.149 & $3.788^{* * *}$ \\
\hline Education level & 1.962 & 2.246 & 1.708 & $-8.059^{* * *}$ & 2.317 & 1.677 & $-9.887^{* * *}$ \\
\hline Illiteracy & 0.144 & 0.087 & 0.202 & $4.983^{* * *}$ & 0.059 & 0.204 & $6.565^{* * *}$ \\
\hline Primary school & 0.131 & 0.085 & 0.159 & $3.431^{* * *}$ & 0.101 & 0.167 & $2.919^{* * *}$ \\
\hline Junior high school & 0.346 & 0.324 & 0.367 & 1.376 & 0.305 & 0.377 & $2.301^{* *}$ \\
\hline High school and above & 0.380 & 0.505 & 0.272 & $-7.505^{* * *}$ & 0.535 & 0.252 & $-9.247^{* * *}$ \\
\hline Nationality & 0.101 & 0.085 & 0.115 & 1.541 & 0.085 & 0.115 & 1.541 \\
\hline Occupation & 0.627 & 0.660 & 0.534 & $-2.781^{* * *}$ & 0.847 & 0.506 & $-7.236^{* * *}$ \\
\hline Unemployed & 0.511 & 0.533 & 0.520 & -0.396 & 0.430 & 0.554 & $3.793^{* * *}$ \\
\hline Ordinary workers & 0.351 & 0.275 & 0.427 & $4.875^{* * *}$ & 0.293 & 0.387 & $3.001^{* * *}$ \\
\hline Senior management & 0.138 & 0.192 & 0.0540 & $-6.712^{* * *}$ & 0.277 & 0.060 & $-9.447^{* * *}$ \\
\hline Town & 0.557 & 0.610 & 0.512 & $-3.022^{* * *}$ & 0.610 & 0.512 & $-3.022^{* * *}$ \\
\hline Family size & 3.461 & 3.300 & 3.605 & $3.466^{* * *}$ & 3.232 & 3.647 & $4.365^{* * *}$ \\
\hline Any other relatives & 0.959 & 0.974 & 0.96 & -1.173 & 0.958 & 0.944 & -0.932 \\
\hline Household income per capita & 12280.28 & 12125.36 & 8450.34 & $-5.614^{* * *}$ & 18724.76 & 10788.13 & $-9.816^{* * *}$ \\
\hline Smoking & 0.281 & 0.254 & 0.304 & $1.693^{*}$ & 0.261 & 0.300 & 1.318 \\
\hline Alcohol & 0.123 & 0.115 & 0.131 & 0.735 & 0.127 & 0.117 & -0.451 \\
\hline Illness or injury & 0.096 & 0.075 & 0.117 & $2.148^{* *}$ & 0.082 & 0.105 & 1.194 \\
\hline Previous medical history & 0.178 & 0.188 & 0.137 & $-2.111^{* *}$ & 0.223 & 0.173 & $-1.931^{*}$ \\
\hline
\end{tabular}

TABLE 3: The calculation principle of DID.

\begin{tabular}{lccc}
\hline & Phase 1 (time $=0)$ & Phase 2 (time $=1)$ & Difference \\
\hline Treatment group (treat $=1)$ & $\beta_{0}^{\prime}+\beta_{1}^{\prime}$ & $\beta_{0}^{\prime}+\beta_{1}^{\prime}+\beta_{2}^{\prime}+\beta_{3}^{\prime}$ & $\beta_{2}^{\prime}+\beta_{3}^{\prime}$ \\
Control group (treat $=0)$ & $\beta_{0}^{\prime}$ & $\beta_{0}^{\prime}+\beta_{2}^{\prime}$ & $\beta_{1}^{\prime}$ \\
Difference & $\beta_{1}^{\prime}$ & $\beta_{1}^{\prime}+\beta_{3}^{\prime}$ & $\beta_{3}^{\prime}$ (DID) \\
\hline
\end{tabular}

insured choose not to seek medical treatment until suffering from serious illness, thus reducing the utilization of medical services. However, for the insureds who have incurred medical expenses, the expenses they actually paid rose sharply. The net effect of UEBMI led to a $234 \%$ increase in total medical expenses, which is significant at a $5 \%$ confidence level. On the other hand, self-paid medical expenses equal the total medical expenses minus the reimbursement amount of medical insurance. In case of the increase in the total medical expenses, after deducting the reimbursement amount of medical insurance, UEBMI still contributed to a $110.64 \%$ increase in self-paid medical expenses, although the result is not significant.

3.2. Robustness Test. In order to ensure the reliability of the above results, this paper reuses the fixed effect model to test the impact of UEBMI on total medical expenses and selfpaid medical expenses. The results are shown in Table 5.

The results of robustness test are similar to those of Heckman sample selection model. The expenses paid by the insured who incurred medical expenses will increase significantly. The net effect of UEBMI led to an increase of $180.39 \%$ in total expenses and $83.86 \%$ in self-paid medical expenses.

\section{The Mechanism Analysis of Medical Expenses Growth}

This paper argues that there are three reasons for the sharp increase in total medical expenses and self-paid medical expenses caused by UEBMI: (1) The release of normal medical needs: because UEBMI reduces the medical prices, some insureds who once cannot afford healthcare can now seek medical attention, which increases their medical expenses. (2) The result of adverse selection: that is, people with poor health are more inclined to buy medical insurance, so the number of illnesses increases and the medical expenses increase. (3) The result of moral hazard: that is, after purchasing medical insurance, consumers can enjoy medical services at a lower price; then, they are not very sensitive to 
TABLE 4: Empirical results of Heckman sample selection model.

\begin{tabular}{|c|c|c|c|c|}
\hline \multirow[b]{2}{*}{ Variable } & \multicolumn{2}{|c|}{ Logarithm of total medical expenses } & \multicolumn{2}{|c|}{ Logarithm of self-paid medical expenses } \\
\hline & $\begin{array}{c}\text { (1) } \\
\text { Selection equation }\end{array}$ & $\begin{array}{c}(2) \\
\text { Expenditure equation }\end{array}$ & $\begin{array}{c}\text { (3) } \\
\text { Selection equation }\end{array}$ & $\begin{array}{c}(4) \\
\text { Expenditure equation }\end{array}$ \\
\hline $\begin{array}{l}\text { Interaction effect } \\
\text { (Treat } \times \text { time })\end{array}$ & $\begin{array}{l}-0.0209 \\
{[0.0206]}\end{array}$ & $\begin{array}{c}1.206^{* *} \\
{[0.6120]}\end{array}$ & $\begin{array}{l}-0.0209 \\
{[0.0206]}\end{array}$ & $\begin{array}{c}0.745 \\
{[0.5823]}\end{array}$ \\
\hline Logarithm of income & $\begin{array}{l}0.00143 \\
{[0.0053]}\end{array}$ & $\begin{array}{l}-0.252^{*} \\
{[0.1296]}\end{array}$ & $\begin{array}{l}0.00143 \\
{[0.0053]}\end{array}$ & $\begin{array}{l}-0.228^{*} \\
{[0.1234]}\end{array}$ \\
\hline Previous medical history & $\begin{array}{c}0.0373^{* * *} \\
{[0.0126]}\end{array}$ & $\begin{array}{l}-0.0759 \\
{[0.4803]}\end{array}$ & $\begin{array}{c}0.0373^{* * *} \\
{[0.0126]}\end{array}$ & $\begin{array}{c}0.0961 \\
{[0.4622]}\end{array}$ \\
\hline Illness or injury & $\begin{array}{l}0.255^{* * *} \\
{[0.0143]}\end{array}$ & $\begin{array}{c}-5.599 \\
{[4.3940]}\end{array}$ & $\begin{array}{l}0.255^{* * *} \\
{[0.0143]}\end{array}$ & $\begin{array}{l}-4.275 \\
{[4.2515]}\end{array}$ \\
\hline Any other relatives & $\begin{array}{l}-0.0326 \\
{[0.0259]}\end{array}$ & & $\begin{array}{l}-0.0326 \\
{[0.0259]}\end{array}$ & \\
\hline Inverse Mills ratio & & $\begin{array}{c}-15.51 \\
{[10.9397]}\end{array}$ & & $\begin{array}{c}-12.08 \\
{[10.5715]}\end{array}$ \\
\hline Constant & & $\begin{array}{c}19.29^{*} \\
{[9.9237]}\end{array}$ & & $\begin{array}{c}16.15^{*} \\
{[9.6066]}\end{array}$ \\
\hline Provinces & $\begin{array}{c}\text { Control } \\
1836\end{array}$ & Control & $\begin{array}{c}\text { Control } \\
1836\end{array}$ & Control \\
\hline
\end{tabular}

Note:the selection equations of models (1) and (3) are estimated by probit model, which gives marginal effect. The standard errors are shown in brackets, and the standard errors of models (2) and (4) are obtained by bootstrap method. The model also controls the variables of age, gender, nationality, marital status, education level, occupation, permanent address, smoking, and drinking. ${ }^{*} P<0.1,{ }^{*}{ }^{*} P<0.05$, and ${ }^{*} * * P<0.01$.

the price of medical services, so they generally have the psychological tendency of "overconsumption," and the consumption motivation of "the more the better" [18], such as overexamination, overmedication, and other behaviors, resulting in an increase in medical expenses. The contribution to medical expenses of these three reasons can be analyzed by income heterogeneity and occupation heterogeneity.

4.1. Income Heterogeneity Analysis. In this paper, household income per capita is ranked. The bottom third of households are classified as low-income families, the middle third of households are classified as middle-income families, and the top third of households are classified as high-income families. The results in the above table show that after purchasing UEBMI, low-income and middle-income families are less likely to incur positive medical expenses, but the results are not significant. The probability of positive medical expenses in high-income families will increase slightly, and the results are also not significant. The results indicate that UEBMI plays a very limited role, and it does not effectively change the utilization rate of medical services of the insureds. The results in Table 6 indicate that it is true that medical insurance leads to an increase in medical expenses. Even if the insured has medical insurance to reimburse part of the medical expenses, the actual amount paid in the end is higher than that before the insurance, which makes the insured with lower income choose not to seek medical treatment without serious illness, thus reducing the utilization of medical services.

For the insureds who have incurred medical expenses, the coefficients of interaction effect are not significant, which indicates that the role of medical insurance is limited. There is no significant release of normal medical demand, no significant increase in the utilization rate of medical services, no significant increase in medical expenditure, and no significant reduction in self-paid medical expenditure. However, the role of UEBMI varies widely among families with different incomes. Low-income families are most likely to "become poor due to illness and return to poverty due to illness." Because medical insurance can help those most in need, it can release the demand of patients who originally "cannot afford healthcare," resulting in an increase of $0.61 \%$ in total medical expenses and a decrease of $63.98 \%$ in self-paid medical expenses. Normal medical demand has changed little, but the UEBMI has played an important role in economic compensation for low-income families. Middle-income families can pay medical expenses without medical insurance, so the increase in medical expenses mainly comes from moral hazard, leading to an increase of $114.47 \%$ in total expenses and $63.56 \%$ in self-paid medical expenses. On the contrary, the medical expenses paid by higher-income families decrease, because they pay more attention to daily healthcare, the probability of serious illness decreases, and the corresponding medical expenses decrease too.

4.2. Occupation Heterogeneity Analysis. The "Decision on Establishing the System of Basic Medical Insurance for Urban Employees" clearly requires workers who have a regular job to "be forced" to participate in UEBMI with the unit as the carrier. In this case, the insureds cannot freely choose whether to participate in the insurance according to their health status, and there is no adverse selection. However, those who have no fixed work, that is, flexible employees, can freely choose whether to participate in medical insurance and can also freely choose to participate in medical insurance for urban employees or medical insurance for urban and rural residents. In other words, this group of people is likely to choose whether to participate in 
TABLE 5: Regression results of fixed effect model.

\begin{tabular}{|c|c|c|c|c|}
\hline \multirow{2}{*}{ Variable } & \multicolumn{2}{|c|}{ Logarithm of total medical expenses } & \multicolumn{2}{|c|}{ Logarithm of self-paid medical expenses } \\
\hline & Coefficient & Standard error & Coefficient & Standard error \\
\hline Interaction (treat $\times$ time) & $1.031^{*}$ & 0.5557 & 0.609 & 0.5274 \\
\hline Treatment effect (treat) & -0.504 & 0.392 & -0.544 & 0.3721 \\
\hline Time effect (time) & 0.224 & 0.3448 & 0.206 & 0.3273 \\
\hline Provinces & \multicolumn{2}{|c|}{ Control } & \multicolumn{2}{|c|}{ Control } \\
\hline Sample size & \multicolumn{2}{|c|}{213} & \multicolumn{2}{|c|}{213} \\
\hline
\end{tabular}

*Statistical significance at the $10 \%$ level. Control variables include age, square of age, gender, nationality, marital status, education level, occupation, permanent address, income, previous medical history, smoking, and drinking.

TABLE 6: Release effect of normal medical needs.

\begin{tabular}{|c|c|c|c|c|c|c|c|}
\hline & \multirow[b]{2}{*}{ Variable } & \multicolumn{2}{|c|}{ Low-income families } & \multicolumn{2}{|c|}{ Middle-income families } & \multicolumn{2}{|c|}{ High-income families } \\
\hline & & $\begin{array}{c}(1) \\
\text { Selection } \\
\text { equation } \\
\end{array}$ & $\begin{array}{c}\text { (2) } \\
\text { Expenditure } \\
\text { equation }\end{array}$ & $\begin{array}{l}\text { (3) } \\
\text { Selection } \\
\text { equation }\end{array}$ & $\begin{array}{l}\text { (4) } \\
\text { Expenditure } \\
\text { equation }\end{array}$ & $\begin{array}{l}\quad(5) \\
\text { Selection } \\
\text { equation } \\
\end{array}$ & $\begin{array}{c}(6) \\
\text { Expenditure } \\
\text { equation }\end{array}$ \\
\hline \multirow{7}{*}{$\begin{array}{l}\text { Explained variable: } \\
\text { logarithm of total medical } \\
\text { expenses }\end{array}$} & $\begin{array}{c}\text { Interaction } \\
\text { effect }\end{array}$ & -0.0398 & 0.00611 & -0.0337 & 0.763 & 0.00776 & -0.0949 \\
\hline & (Treat $\times$ time $)$ & {$[0.0544]$} & [2.6589] & {$[0.0312]$} & [1.4655] & {$[0.0369]$} & [1.9022] \\
\hline & $\begin{array}{l}\text { Treatment } \\
\text { effect }\end{array}$ & 0.0254 & -0.114 & 0.0157 & 0.379 & 0.00504 & -1.28 \\
\hline & (Treat) & {$[0.0347]$} & [1.2680] & {$[0.0218]$} & {$[0.9869]$} & {$[0.0280]$} & [1.2413] \\
\hline & Time effect & -0.0095 & $\begin{array}{c}0.442 \\
{[06081]}\end{array}$ & 0.00968 & $\begin{array}{c}1.186 \\
{[08388]}\end{array}$ & -0.0228 & $\begin{array}{c}1.207 \\
{[1.4551]}\end{array}$ \\
\hline & $\begin{array}{l}\text { Constant } \\
\text { term }\end{array}$ & & 2.706 & & 9.027 & & 35 \\
\hline & (_ cons) & & {$[23.4859]$} & & {$[13.3360]$} & & {$[34.0406]$} \\
\hline \multirow{10}{*}{$\begin{array}{l}\text { Explained variable: } \\
\text { logarithm of self-paid } \\
\text { medical expenses }\end{array}$} & $\begin{array}{c}\text { Interaction } \\
\text { effect }\end{array}$ & -0.0398 & -1.021 & -0.0337 & 0.492 & 0.00776 & -0.554 \\
\hline & (Treat $\times$ time $)$ & {$[0.0544]$} & [2.5011] & {$[0.0312]$} & [1.4032] & {$[0.0369]$} & [1.7911] \\
\hline & $\begin{array}{l}\text { Treatment } \\
\text { effect }\end{array}$ & 0.0254 & -0.194 & 0.0157 & 0.324 & 0.00504 & -1.352 \\
\hline & (Treat) & {$[0.0347]$} & {$[1.2274]$} & {$[0.0218]$} & {$[0.9537]$} & {$[0.0280]$} & [1.1713] \\
\hline & Time effect & -0.0095 & 0.45 & 0.00968 & 1.259 & -0.0228 & 0.961 \\
\hline & (Time) & {$[0.0249]$} & {$[0.5956]$} & {$[0.0233]$} & {$[0.8217]$} & {$[0.0302]$} & [1.2927] \\
\hline & $\begin{array}{c}\text { Constant } \\
\text { term }\end{array}$ & & 3.438 & & 8.901 & & 26.84 \\
\hline & (_ cons) & & {$[22.7362]$} & & [12.9894] & & {$[30.8461]$} \\
\hline & Provinces & Control & Control & Control & Control & Control & Control \\
\hline & Sample size & 453 & 64 & 710 & 82 & 632 & 67 \\
\hline
\end{tabular}

Note: the selection equations of models (1), (3), and (5) are estimated by probit model, which gives marginal effect. The standard errors are in brackets, and the standard errors of models (2), (4), and (6) are obtained by bootstrap method. The control variables of the expenditure equation include age, square of age, gender, nationality, marital status, education level, occupation, permanent address, income, previous medical history, smoking, and drinking. The control variables of the selection equation also add whether there are other relatives.

insurance according to their own health status, resulting in adverse selection. The empirical results in Table 7 show that the medical expenses of samples with fixed jobs, that is, the mandatory participants, reduced slightly, while the total medical expenses of those who have no fixed job, that is, the flexible employees, significantly increased by $364.6 \%$, and the self-paid medical expenses increased by $153.96 \%$. The results of income heterogeneity analysis show that medical expenses only increased by $0.61 \%$ due to the release of normal demand. Then, the increase in medical expenses can be mainly attributed to adverse selection and moral hazard, of which moral hazard led to an increase of $114.47 \%$ in total medical expenses and $63.56 \%$ in self-paid medical expenses. For flexible employees, adverse selection led to an increase of $249.52 \%$ in total medical expenses and $90.4 \%$ in self-paid medical expenses. 
TABLE 7: Adverse selection and moral hazard effect.

\begin{tabular}{|c|c|c|c|c|c|}
\hline & \multirow[b]{2}{*}{ Variable } & \multicolumn{2}{|c|}{ Having a regular job } & \multicolumn{2}{|c|}{ No fixed work } \\
\hline & & $\begin{array}{c}\text { (1) } \\
\text { Selection } \\
\text { equation }\end{array}$ & $\begin{array}{c}\text { (2) } \\
\text { Expenditure } \\
\text { equation }\end{array}$ & $\begin{array}{c}(3) \\
\text { Selection } \\
\text { equation }\end{array}$ & $\begin{array}{c}\text { (4) } \\
\text { Expenditure } \\
\text { equation }\end{array}$ \\
\hline \multirow{6}{*}{$\begin{array}{l}\text { Explained variable: logarithm of total medical } \\
\text { expenses }\end{array}$} & $\begin{array}{l}\text { Interaction } \\
\text { effect }\end{array}$ & 0.0117 & -1.185 & -0.0408 & $1.536^{*}$ \\
\hline & (Treat $\times$ time $)$ & {$[0.0248]$} & {$[1.5332]$} & {$[0.0338]$} & {$[0.8333]$} \\
\hline & $\begin{array}{l}\text { Treatment } \\
\text { effect }\end{array}$ & 0.00655 & -1.218 & 0.0048 & -0.557 \\
\hline & (Treat) & {$[0.0178]$} & {$[0.8718]$} & {$[0.0244]$} & [0.5428] \\
\hline & Time effect & -0.0197 & 0.826 & -0.00391 & 0.124 \\
\hline & (Time) & {$[0.0175]$} & {$[0.9482]$} & {$[0.0221]$} & {$[0.4453]$} \\
\hline \multirow{8}{*}{$\begin{array}{l}\text { Explained variable: logarithm of self-paid } \\
\text { medical expenses }\end{array}$} & $\begin{array}{l}\text { Interaction } \\
\text { effect }\end{array}$ & 0.0117 & -1.146 & -0.0408 & 0.932 \\
\hline & $($ Treat $\times$ time $)$ & {$[0.0248]$} & [1.4467] & {$[0.0338]$} & [0.7869] \\
\hline & $\begin{array}{l}\text { Treatment } \\
\text { effect }\end{array}$ & 0.00655 & $-1.328^{*}$ & 0.0048 & -0.538 \\
\hline & (Treat) & {$[0.0178]$} & {$[0.7902]$} & {$[0.0244]$} & [0.5396] \\
\hline & Time effect & -0.0197 & 0.769 & -0.00391 & 0.115 \\
\hline & (Time) & {$[0.0175]$} & {$[0.9180]$} & {$[0.0221]$} & {$[0.4404]$} \\
\hline & Provinces & Control & Control & Control & Control \\
\hline & Sample size & 898 & 78 & 933 & 135 \\
\hline
\end{tabular}

*Statistical significance at the $10 \%$ level. The selection equations of models (1) and (3) are estimated by probit model, which gives marginal effect. The standard errors are in brackets, and the standard errors of models (2) and (4) are obtained by bootstrap method. The control variables of the expenditure equation include age, square of age, gender, nationality, marital status, education level, occupation, permanent address, income, previous medical history, smoking, and drinking. The control variables of the selection equation also add whether there are other relatives.

\section{Conclusions}

By constructing Heckman sample selection model, this paper finds that after purchasing UEBMI, the medical expenses of the insureds increase greatly. The net effect of UEBMI led to an increase of $234 \%$ in total medical expenses and $110.64 \%$ in self-paid medical expenses. According to the results, UEBMI not only fails to play an important role in the economic compensation function, but also increases the economic burden of the insureds. In fact, there are three reasons for the increase of medical expenses: the release of normal medical demand, adverse selection, and moral hazard. This paper holds that when the insured gets a low income, the moral hazard is not a problem, and the increase of medical expenses can mainly be attributed to the release of normal medical demand, resulting in an increase of $0.61 \%$ in medical expenses. Flexible employees without a fixed job can freely choose whether to participate in insurance or not; thus, there may be adverse selection problems. On the other hand, workers with fixed jobs are forced to take the unit as the carrier to participate in UEBMI, and basically there is no adverse selection problem; thus, the increase in medical expenses can be attributed to moral hazard. Therefore, this paper concludes that moral hazard led to an increase of $114.47 \%$ in total medical expenses and $63.56 \%$ in self-paid medical expenses. For flexible employees, adverse selection led to an increase of $249.52 \%$ in total medical expenses and $90.4 \%$ in self-paid medical expenses.

This paper finds that the problems of adverse selection and moral hazard are very prominent in UEBMI, and puts forward some suggestions as follows: First, Hierarchical Treatment Model should be promoted to control the growth of medical expenses. In order to reduce patients' medical expenses and ease their medical burden, we can use medical insurance to speed up the process of Hierarchical Treatment Model, guide insureds to "seek downward medical treatment," and determine a scientific payment system [19]. Second, flexible employees should be guided to participate in the UEBMI. Due to the limited conditions of participating in insurance, weak awareness of participating in insurance, and difficulties in transfer and connection, the participation rate of flexible employees is not high [20]. For the sake of guiding them to actively participate in insurance, we can increase the publicity of medical insurance and health policies and build carriers of communities, labor dispatch companies, and trade associations. Because compulsory insurance is an effective way to solve the problem of adverse selection, flexible employees are required to purchase group insurance on a carrier basis, which means adopting internal compulsory insurance, to form a de facto compulsory insurance to solve the problem of adverse selection [21].

\section{Data Availability}

The raw data used to support the findings of this study can be obtained upon application to the website of China Health and Nutrition Survey. The processed data are available upon request from the corresponding author.

\section{Conflicts of Interest}

The authors declare that there are no conflicts of interest regarding the publication of this study. 


\section{Acknowledgments}

This paper was supported by Social Sciences Research Planning Project of the Ministry of Education "Empirical Test and Control Strategy of Farmers' Moral Hazard in the Pilot of Grain Crop Full-Cost Insurance: Based on the Investigation of Pilot Counties in Shandong and Hubei Province" (21YJA790032) and the Fundamental Research Funds for the Central Universities (Humanities and Social Sciences Research Project of Wuhan University).

\section{References}

[1] J. Pan, X. Lei, and G. Liu, "Does health insurance lead to better health?" Economic Research Journal, vol. 48, no. 4, pp. 130-142, 2013.

[2] W. G. Manning, "Health insurance and the demand for medical care: evidence from a randomized experience," The American Economic Review, vol. 77, no. 3, pp. 251-277, 1987.

[3] X. Lei and W. Lin, "The new cooperative medical scheme in rural China: does more coverage mean more service and better health?" Health Economics, vol. 18, no. S2, pp. S25-S46, 2009.

[4] J. Feng, F. Liu, and Q. Chen, "Impact of new cooperative medical system on health care price," Economic Research Journal, vol. 45, no. 11, pp. 127-140, 2010.

[5] L. Cheng and Y. Zhang, "The new rural cooperative medical scheme: financial protection or health improvement?" Economic Research Journal, vol. 47, no. 1, pp. 120-133, 2012.

[6] D. Wang, Research on the Effect of Health Insurance Based on Asymmetric Information, University of International Business and Economics, Beijing, China, 2017.

[7] E. Oster, I. Shoulson, K. A. Quaid et al., "Genetic approach selection: evidence from long-term care insurance and huntington disease," Journal of Public Economics, vol. 94, no. 11, pp. 1041-1050, 2010.

[8] M. Eling, R. Jia, and Y. Yao, "Between-group adverse selection: evidence from group critical illness insurance," Journal of Risk \& Insurance, vol. 84, no. 2, pp. 771-809, 2017.

[9] S. Ahmed, A. Sarker, M. Sultana et al., "Adverse selection in community based health insurance among informal workers in Bangladesh: an EQ-5D assessment," International Journal of Environmental Research and Public Health, vol. 15, no. 2, p. 242, 2018.

[10] X. Zhu and T. Peng, "Adverse selection in new rural cooperative medical scheme: theoretical research and empirical analysis," Management World, vol. 1, pp. 79-88, 2009.

[11] W. Zang, S. Zhao, and G. Liu, "The analysis of adverse selection in China's urban basic medical insurance programs," China Economic Quarterly, vol. 1, pp. 47-70, 2013.

[12] W. Wang and Y. Yang, "An empirical analysis on the impacts of consumer heterogeneity on health insurance adverse selection," Insurance Studies, vol. 8, pp. 47-63, 2018.

[13] K. J. Arrow, "Uncertainty and the welfare economics of medical care," The American Economic Review, vol. 53, no. 5, pp. 941-973, 1963.

[14] J. H. Cardon and I. Hendel, "Asymmetric information in health insurance: evidence from the national medical expenditure survey," The RAND Journal of Economics, vol. 32, no. 3, pp. 408-427, 2001.

[15] F. Huang and L. Gan, "Research on moral hazard in medical insurance: based on analysis of micro-data," Journal of Financial Research, vol. 5, pp. 193-206, 2012.
[16] M. Xie and M. Zhu, "A study of the threshold effect of medical insurance on medical expenses," Journal of Jiangxi University of Finance and Economics, vol. 4, pp. 57-65, 2016.

[17] Q. Zhou and G. Liu, "Health shock: what did current health insurance system do?" Economic Review, vol. 6, pp. 78-90, 2014.

[18] B. Zheng, "Information asymmetry and medical insurance," Comparative economic \& social systems, vol. 6, pp. 8-15, 2002.

[19] Q. Fu, "Strategic choice for promoting hierarchical treatment model," Chinese Health Economics, vol. 34, no. 2, pp. 28-31, 2015.

[20] Y. Qiu and X. Ran, "The difficulty of participation in medical insurance for flexible employees," China Health Insurance, vol. 1, pp. 6-8, 2020.

[21] J. Liu, Q. Shuai, and G. Lv, "The difficulties of flexible employees participating in medical insurance: based on analysis of adverse selection," On Economic Problems, vol. 1, pp. 66-70, 2016. 